This item was submitted to Loughborough's Research Repository by the author.

Items in Figshare are protected by copyright, with all rights reserved, unless otherwise indicated.

\title{
Arsene didn't see it: coaching, research and the promise of a discursive psychology
}

PLEASE CITE THE PUBLISHED VERSION

http://dx.doi.org/10.1260/1747-9541.7.4.615

PUBLISHER

(C) Multi-Science Publishing Co Ltd

VERSION

VoR (Version of Record)

LICENCE

CC BY-NC-ND 4.0

REPOSITORY RECORD

Potter, Jonathan. 2019. “Arsene Didn't See It: Coaching, Research and the Promise of a Discursive Psychology”. figshare. https://hdl.handle.net/2134/15076. 


\title{
Arsène Didn't See lt: Coaching, Research and the Promise of a Discursive Psychology
}

\author{
Paul K. Miller \\ Faculty of Health \& Wellbeing, \\ University of Cumbria \\ Bowerman Road, Lancaster, LA1 3JD, UK \\ E-mail: paul.miller@cumbria.ac.uk
}

\begin{abstract}
For twenty five years the discursive psychological perspective has been at the vanguard of innovative research in social psychology, producing highdetail systematic analyses of dynamic, constructive language use in a wide range of practical settings. To date, it has found applications in the study of medical communication, racism, political discourse, emotion and accounts of success and failure in sport, to highlight but a few. Its lack of headway in the specific study of coaching is perhaps, therefore, somewhat surprising given the transparently task-focused character of many naturally-occurring verbal activities in the domain. This article draws on salient literature and two brief case studies in illustrating some of the ways that the perspective can inform an approach to coaching interaction that does not draw on ontologically-problematic cognitivist assumptions regarding the relationship between thought and action. A foundational argument is then made for greater engagement with discursive psychology within the broader realm of coaching science.
\end{abstract}

Key words: Cognition, Conversation Analysis, Discursive Psychology, Language, Sports Coaching

\section{INTRODUCTION}

It has become something of a canonical truism for anyone who follows the English Premier League that Arsenal FC coach Arsène Wenger, whenever quizzed in a post-match interview about a possible misdemeanour committed by any of his own players during the preceding 90 minutes, will most likely claim to have "not seen" the pertinent incident. For example, when asked to comment upon an on-field altercation between Arsenal teammates Emmanuel Adebayor and Nicklas Bendtner during a League Cup tie with local rivals Tottenham Hotspur in 2008, Wenger explicitly declared "I did not know anything about it. I didn't see it," at which point the questioning turned to other matters. Intuitively, as social scientists, we may well find ourselves questioning the veracity of this claim. Did Wenger, we might ask, really not see what happened, and was therefore unable to answer questions regarding the incident? Or, more insidiously, did he actually see everything and only claim ignorance such that he would not then have to answer questions regarding the incident? In order to unpick 
to the mystery of Wenger's honesty (and/or memory) here, we would need to grasp the character of the actual reality he is talking about [1]. Was Wenger actually looking at the events in question at the time they occurred? Was he close enough to see properly? Was his view obstructed? Did he blink at the moment it happened? If the words and the world "match-up," Wenger can be said to be telling the truth. If they are apparently at odds, then we can assert that he is either mistaken, his recall is malfunctioning or (if we surmise he has motivation to do so) he is actually lying. As Derek Edwards [2] summarises, from this intuitive, social-cognitive point of view:

Cognition and reality are like two sides of a coin. If we want to know about cognition, we need to take account of the world, hold reality constant and vary it systematically, so that we can discern the workings of the mind. If we want to know about reality, it is cognition and other human foibles that have to held constant or under control. We have to assure ourselves that we are not deluded, mistaken or misinformed, seeing what we expect or want to see, and this may require systematic methods for countering the vagaries of the mind. [2, p. 10]

There are, however, two key complications in assessing the truth of Wenger's claim using this mode of reasoning:

1. What if it is not possible to discern a singular "truth" here? What if we cannot say for certain whether or not the incident was actually seen? In such a case, how can provide a firm assessment of the status of Wenger's claim?

2. If we are to presume that the ways in which Wenger processes reality are fallible, partial and/or subject to fabrication, how can we place such total faith in our own capacity, as analysts, to discern the same reality objectively? How can we confidently assert that our claims regarding "what he actually saw" are more reliable than his own? Are we not also subject to partiality, subjectivity and bias? Assessing the "truth" of any claim becomes a rather greater problem if we consider "...reality to be itself a product of human perceptions, artefacts, practices and accounts." [2, p. 10; emphases original]

The first of these issues gives us cause to question the limits of our own assertions; the second asks of us whether we can (or should) really be making those assertions with any confidence at all [3]. What we can assert with absolute clarity in this case, however, is that through the making of the claim that he "didn't see" (be it true or false):

1. Wenger's situated responsibility to answer any further questions relating directly to the incident was systematically negated. The interviewer did not (and could not reasonably) expect him to comment authoritatively upon an incident he has not seen with his own eyes, so to speak. Indeed, for the interviewer to continue pursuing the topic in the light of Wenger's claim would have risked implying that the Arsenal coach was, in fact, not being entirely honest.

2. This, in turn, forestalled the likelihood of Wenger having to perform any connected and potentially problematic or embarrassing verbal actions such as, for example, having to actively criticise (or excuse) Adebayor and/or Bendtner in a public forum.

Thus, while we can run into serious problems when attempting to divine the absolute "truth" 
in Wenger's claim, it is perfectly possible for us to describe what that claim methodically does, as an interpersonal action, during this interview. Fundamentally, it makes it very (socially) difficult for the interviewer to extract any further details regarding (or related to) the incident without to some extent implying (in front of an audience) that Wenger has, in fact, lied. Or, to view it from another perspective, Wenger placed the interviewer in a position whereby he could either: a) "drop" the topic, or, b) pursue an inferably hostile course of verbal action that could well have threatened the "local social solidarity" [4]; i.e. breach a commonly-understood normative standard of conduct in conversation. Wenger exerted a normative pressure [5] upon the interviewer to move the conversation along to other matters.

\section{HARVEY SACKS, CONVERSATION AND PSYCHOLOGY}

This short analysis of an exchange between an interviewer and a professional coach parallels some pathbreaking observations made by Harvey Sacks [5], initially during a study of telephone calls to a suicide prevention centre in the 1960s. The manifest problem identified by staff at this centre was with getting callers to identify themselves. As standard practice, at the beginning of any call, staff members would introduce themselves by name; in some cases, the caller would give their own name in reply. Some would not, however, and some would even refuse to do so when explicitly asked for a name further into the conversation. For Sacks, this raised the issue of when, in such a conversation, it might become apparent to a speaker that the other person was withholding their name, which in turn led him to consider the following opening exchange in an analytically novel manner:

Extract 1: (from Sacks [5])

1. A: This is Mr Smith, may I help you

2. B: I can't hear you

3. A: This is Mr. $\underline{\text { Smith }}^{1}$

4. B: Smith

The conversation then proceeded, once the "not hearing" had been resolved, without the caller (B) attempting to provide a name in reply. Rather than simply treat the first utterance made by the caller (line 2) as a transparent representation of a problem he was actually having with hearing Mr. Smith, however, Sacks attended to what that utterance was actually doing in the particular situation. Robin Wooffitt [6] elaborates this analysis:

[Sacks] observes that there are norms concerning where in conversation certain kinds of activities should happen; and in conversation between strangers, names tended to be exchanged in initial turns. Developing this, Sacks argues that the caller is using the utterance 'I can't hear you' to fill the slot in the conversation where it would be expected that he return his name. $[6, \mathrm{p} .6]$

This norm is familiar to all of us, if we give it due consideration. The longer a conversation with a stranger persists without us knowing their name, the more socially awkward it becomes to ask for it. Indeed, it becomes progressively more important to apologise for the question; "I'm really sorry, but what was your name again?" By filling the space where his name would normatively be provided with something else, the caller above thereby finds a

${ }^{1}$ Note: within Sacks' own transcription conventions, underlining denotes speaker emphasis. 
practical method for avoiding identifying himself, without actively declining to.

This observation became the foundation of Sacks' entire programme of conversation analytic investigation; exhaustively analysing huge numbers of extracts of naturallyoccurring talk, Sacks argued that even in the most apparently mundane examples of human verbal interaction a distinct, task-directed organisation can be observed:

If...we figure or guess or decide that whatever humans do, they are just another animal after all, maybe more complicated than others but perhaps not noticeably so, then whatever humans do can be examined to discover some way they do it...That is, we may...take it that there is order at all points.' [7, p. 22]

\section{PSYCHOLOGY WITHOUT COGNITION}

To those unfamiliar with Sacks' work, or subsequent work in the paradigm he established, such analysis can appear almost spurious on the grounds that speakers “...couldn't have thought that fast" [5, p. 11]. However, and as Sacks himself forcefully argues, people do not actively pre-script everything they say. In fact, most talk is accomplished "on-the-fly" [2]. Despite this, people still make compelling arguments, execute complex interpersonal tasks and adhere to intricate norms of politeness and conduct. Everyday talk, like many other skills that we have been practicing since childhood, is something we become very good at. Thus, when we study people talking, we should not:

...worry about how fast they're thinking. First of all, don't worry that they're 'thinking'. Just try to come to terms with how it is that the thing comes off.

Because you'll find they can do these things... So just let the materials fall as they may. [5, p. 11]

It is also important to be mindful that what Sacks is expressing here is not in any sense a denial of the role of "mental process" in human activity either; after all someone without a brain could hardly claim to "see," "hear" or "think," and it is extremely doubtful that they would be regularly conversing with others. As Potter and Wetherell warn, there is little profit in becoming embroiled in "...fruitless debates about the reality or non-reality of mental entities, which can easily end up in the kind of linguistic imperialism which denies all significance to cognitive processes" [8, p. 180]. The fundamental principle central to all discursive approaches emanating from Sacks' original work is that the words people speak are not straightforwardly reducible to, or representative of, cognitive operations which mediate the "real world" and an inner representation of it. As such, rather than using the words that people say to deduct cognitive information, the focus for this paradigm is upon the intricate actions that those words accomplish in the social realms that people inhabit. Such actions include, but are by no means limited to, blaming, excusing, inspiring, confronting, explaining, avoiding, enrolling and excluding. When a coach requests that a player "pull their socks up," we would not generally imagine that this represents an "inner" desire to see footwear corrections made. It is recognisable (to those with the right sociocultural frame of reference) as a motivation token.

Similarly, when providing factual descriptions, it is rarely in a coach's interest to simply present a perfectly "neutral" picture of "what happened" (assuming, for one moment, that this were even possible). Language is a vastly flexible tool, we can describe any one situation, person or thought in a wide range of ways without ever appearing to be factually incorrect. As such, our descriptions are themselves formulations, versions of the things that 
can be shown to perform particular functions in particular contexts [9]. Any experienced coach will be fully conversant with the fact that the knowledge they hold, if it is to have the desired import in the business of coaching itself, needs to be reframed and reformulated in line with where it is being produced, for whom and to what ends; there is a necessary element, at the very least, of rhetoric involved [10]. The way a coach relays technique $\mathrm{X}$ to a novice athlete is unlikely to be reflective of the entirety of the coach's knowledge of the topic, but instead reflective of what he or she reasons that athlete will best understand, digest and learn from. It is also, one might reasonably expect, likely to be a rather different account of technique $\mathrm{X}$ to one the same coach might then present to a far more experienced athlete. The former may be extended but simplistic, on the assumption that the novice "audience" is not at all conversant with the materials. The latter, where it can be assumed that the athlete has already been taught the technique, may be truncated and lower on formal explanation, formulated more as a "reminder" than a "lesson." Neither is a transparent representation of the character and extent of the coach's knowledge of the technique itself. The particular character of any piece of knowledge as-it-is-communicated is, thus, contingent upon particular features of the (assumed) context in which it is being communicated ${ }^{2}$. As David Silverman [3] writes, not only does Sacks' work (in this sense) stand in opposition to most contemporary academic treatments of language, it is also quite powerfully counter-intuitive.

Ordinarily, if we think about it at all, we assume that what we say reflects our state of mind. However, what Sacks is showing us is that, in practice, we construct our talk with reference to how it will be heard. By saying what we do, positioned in a particular place, we thus make available to our hearer(s) a particular reading of what we mean. [3, p. 6]

In sum, a discursive psychology of coaching practice needs to recognise that "...to separate talk and action as psychologists commonly do (for example in distinctions such as attitudes vs. behaviour) is to set up a false dichotomy, and to overlook the ways in which talk achieves things in itself" [9, p. 77]. Rather than exclusively ask ourselves what incidences of talk between coaches and athletes might represent, we should seriously consider Sacks' core postulates and, instead, regard them in the way that we regard other forms of action by asking, primarily: (a) "What does the talk do here?" and (b) "How does it do it?"

COACHING, DISCURSIVE PSYCHOLOGY AND SACKS' LEGACY Since his premature death in 1975, Sacks' work has proven profoundly influential in many realms of social science $[3,11,12]$. In its most direct form it has been the basis for the modern discipline of conversation analysis (henceforth CA), a highly technical methodology which has to date been applied in a wide range of domains, and particularly to "institutional" brands of talk (such as those immanent in judicial and medical interaction), including making some inroads in the study of talk in sport [13]. Like the ethnomethodology [14] by which Sacks himself was influenced, CA provides a strong and sustained focus on the unfolding of meaning in situated examples of action, with a view to ultimately describing "architecture of intersubjectivity" [15], the very structures of interaction. Studies in CA primarily address the tacit communicative competences which underpin the production of orderly conversational exchange, the practical kinds of interactional work to which utterances are put and the way that these utterances are designed with respect to the sequences of talk in which they occur. In short,

${ }^{2}$ The same is true of résumés and journal papers. 
CA explores in a fine-grained and stoically empirical manner the local procedures through which everyday life is lived and its meanings produced and reproduced by co-participants in interaction [6, 16-18]. For the most part, however, conversation analysts have been less concerned with the issues of "mind" that are key to the concerns of coaching psychology, and the construction of psychological realities $[19,20]$ that this article primarily addresses. There have been recent exceptions to this trend such as Paul Drew's [21] work on confusion though, as Potter notes, these do sometimes (and contra Sacks' call to "...not worry if they're thinking") attempt to link interactional phenomena to cognitive states, rather than working towards "understanding putatively cognitive phenomena in interactional terms" [19, p. 743].

\section{DISCURSIVE PSYCHOLOGY AND SPORT PSYCHOLOGY}

Potter's final mandate above, to maintain a systematic, non-cognitive approach to conventionally cognitive matters, is the foundational principle of all contemporary discursive psychology (henceforth DP). Drawing heavily upon Sacks' original work [5, 22], and upon many of the subsequent developments in CA, the approach found its first coherent articulation in Potter and Wetherell's seminal Discourse and Social Psychology [8], which functions largely as a critique of the orthodox theories, methodologies and categories employed in cognitive social psychology. In line with Sacks, the authors explore words as actions, and accounts as active constructions, to show how the importance of variations in actual language use between accounts of phenomena have been largely overlooked in psychological studies. Rather than address accounts of "attitudes," for example, as neutral representations of said attitudes, they argue that it is first necessary to address the pragmatic work that the accounts themselves do. People do, after all, have a tendency to espouse apparently contradictory attitudes in different contexts. Descriptions of "internal states" do not, thus, for Potter and Wetherell, give the analyst privileged access to the being of a person. Rather they should be treated as irreducibly social products employed to achieve specific interpersonal goals. By way of a methodological "manifesto," the authors outline six key principles which have obvious ramifications for the investigation of phenomena such as Arsène Wenger's claims to have "not seen" an event (above), and the study of talk in coaching practice in general:

1. Language is used for a variety of functions and its use has a variety of consequences;

2. Language is both constructed and constructive;

3. The same phenomenon can be described in a number of different ways;

4. There will, therefore, be considerable variation in accounts;

5. There is, as yet, no foolproof way to deal with this variation and to sift accounts which are 'literal' or 'accurate' from those which are 'rhetorical' or simply 'misguided' thereby escaping the problems variation raises for researchers with a 'realistic' view of language;

6. The constructive and variable ways in which language is used should themselves become a central topic of study. [8, p. 35]

These core concerns are developed into a more detailed programmatic statement (the "Discursive Action Model") by Edwards and Potter, a general set of principles designed to "orient the psychologist to important features of everyday reports and explanations" [23, p. 155]. This is outlined below: 
Action

1. The focus is upon action, not cognition.

2. Remembering and attribution become, operationally, reportings (and accounts, description, formulations, versions and so on) and the inferences that they make available.

3. Reportings are situated in activity sequences, such as those involving invitation refusals, blamings and defences.

\section{Fact and Interest}

4. There is a dilemma of stake or interest, which is often managed by doing attribution via reports.

5. Reports are often therefore constructed/displayed as factual by way of a variety of discursive techniques.

6. Reports are rhetorically organised to undermine alternatives.

\section{Accountability}

7. Reports attend to the agency and accountability in the reported events.

8. Reports attend to the accountability of the current speaker's action, including those done in reporting.

9. The latter two concerns are often related, such that 7 is deployed for 8 , and 8 is deployed for 7 .

Since these original interventions over two decades ago, DP has generated an extensive and methodologically evolving programme of empirical investigation into a wide range of traditional psychological concerns such as memory [24], attribution [25], emotion [26], decision-making [27] and identity [28], and has been also actively applied to the broader study of sporting phenomena with instructive results [29-32]. Its lack of headway in the specific study of coaching is, however, somewhat surprising given the transparently taskfocused character of many naturally-occurring verbal activities in the domain. Team-talks and performance review meetings, for instance, are not simply (or even necessarily mainly) focused on the technical communication of neutral and factually correct information; rather they are exercises in the strategic deployment of believable detail with a view to making practical differences to the players and the game. As Ludwig Wittgenstein [33] asserted, we should not dwell on the "internal" processes underpinning language-use when, in fact, practice gives words their significance in the social world. A half-time team-talk, it is fair to say, is largely tasked with the motivation of effective action in the second period of play. This may (depending on the specific circumstance) involve foregrounding or backgrounding specific aspects of what has happened so far, phrasing certain issues as positive or negative, making threats and promises or even wilfully lying. The functional point is not whether the claims made are propositionally "true" or "false," "accurate" or "inaccurate," but rather whether they are: a) credibly delivered, i.e. constructed in such a way as to be intelligible and believable given the assumed character of the audience, and b) productive; i.e. they engender some mode of positive outcome. A putatively descriptive statement such as "we can still win this," for example, is almost entirely rhetorical in form as there are very few empirical circumstances in which, halfway through a game, it might not possibly be true (and/or heard as true). Thus, for the psychologist, claims of this order should not be considered transparent (and falsifiable) statements of belief, but as social-psychological tools for the promotion of positive action. 
With these issues in mind, we can finally turn to an issue in the psychology of coaching which bears great promise for discursive investigation.

\section{DP AND COACHING: THE ISSUE OF “EXPERTISE”}

Within many of the contemporary structures of sport itself, the importance of any given individual gaining official modes of certification, the very totems of institutionally-defined expertise, has now become prerequisite to the practices of coaching, teaching and management in sporting life at all but the most casual of levels. For example, since 2003 it has been mandatory for all coaches wishing to take up a position in the English Premier League to hold the UEFA Pro License. This coaching qualification can only be attained following the completion of the UEFA "B" and "A" licenses and, in itself, requires around 240 hours of study over the course of a year, a residential study week at a UK University, plus numerous written examinations and assessed practical sessions.

Often drawing upon K. Anders Ericsson's dominant "expert performance" approach [3436], meanwhile, the contemporary corpus of psychological research into coaching expertise tends to reflect a set of broadly social-cognitive concerns, with specific studies routinely focusing on the conceptualisation and/or measurement of expertise itself [37], and/or influences upon, or obstacles to, the development of such expertise [38, 39]. It is the primary argument herein, however, that the dominance of social-cognitive approaches within the contemporary study of this expertise, and the attendant attempts to produce trans-situational models thereof, has led to a lack of focus on the interpersonal mechanisms through which the key phenomenon is actively, variably and credibly performed within concrete social practices. To neglect the manner in which "expert knowledge" is itself made interpersonally available to others in such a way as to be recognisably expert in-context leaves us with something of a "tree falling in the forest" dilemma. In short, it is one thing for me to accumulate vast reams of useful and specialised domain-specific (i.e., "expert") knowledge. It is another entirely to impart it to a pertinent audience in such a way as to convey my own authority with respect to that knowledge, and to reinforce my authenticity as a credible expert.

In these terms, expertise is only really evident (and therefore possible to evaluate) in its practical, interpersonal performance; we are not as yet in a position where we can neurologically map the dimensions of specific bodies of knowledge "under the skull" [40, p. $100]^{3}$. Moreover, effective interpersonal performance relies upon skills that are not an inevitable upshot of the acquisition of propositional, domain-specific knowledge itself. To fully demonstrate my mathematical expertise during an examination, for example, I need not only to acquire and understand the pertinent mathematical knowledge, but to be able to cope with the particular exam context itself, use the time effectively, and so forth. Failure to do so may well result in outcomes which suggest to others that I am not actually good at maths at all. To be a successful soccer coach, meanwhile, I need to have extensive and flexible knowledge of tactics and strategies, for sure, but if I am unable to deploy (or 'occasion') this knowledge in a manner that the players can themselves understand, internalise and execute in practical circumstances, the knowledge itself comes to naught. Furthermore, my capacity to retain and apply extensive high-level tactical information will not, in and of itself, necessarily motivate the players, inspire them or win their trust.

The real-world impact of specialised knowledge - or indeed any knowledge - is always,

\footnotetext{
${ }^{3}$ Even if we were, it is unlikely that this would be the prime arbiter of how people evaluate each other's expertise in practical social life.
} 
therefore, to some extent contingent upon a broader set of practical and vividly social skills, not least those involved in contextual interpretation and linguistic communication $[9,14,19]$, and there can be little dispute that the primary manner in which expert knowledge in coaching is contextually transferred in coaching is through the use of language, both spoken and written. Below, one method for verbally performing expertise is discussed from a discursive psychological perspective, with a particular view to highlighting how the character of authoritative knowledge as-produced is always indivisibly bound to the social context of its production.

\section{"DOING" EXPERTISE IN CHALLENGING COACHING SITUATIONS: AUTHENTICITY IN AUTOBIOGRAPHY}

The findings briefly discussed below emerge from pilot investigations into the language of team-talks, utilising examples procured both from mediated documentary sources and direct field research in a variety of sports. Early findings indicate a range of highly nuanced and skilled interpersonal methods used by coaches in constituting their knowledge and, reflexively, themselves as authentically and authoritatively "expert," one of which is outlined below.

In a study of accounts of subcultural affiliation, Widdecombe and Wooffitt [41] observe in great detail how speakers, in situations where they infer their own identity as a "proper" punk, goth etc. might be challenged, often go to great lengths to select and foreground highly specific autobiographical details that hearably speak to their own status as "the real deal," as it were. This "authenticity in autobiography" [41] is also far from an uncommon form of talking in the discourse of soccer fandom. Supporters of successful clubs that are thought to attract large numbers of "fairweather fans," such as Manchester United, will often load their accounts of "which team they support" with very specific details pertaining to duration of affiliation to the club, attendance at specific games, holding of season tickets, knowledge of club history, and so forth. All of these, to a co-interlocutor with a common socio-cultural frame of reference, can hearably serve to differentiate the "true" fan from the fairweather variety by explicitly drawing attention to quantities of time and effort invested. Moreover, the particular use of such detail is, in turn, indicative of the speaker having reasoned that there is a culturally-available "dubiousness" in making the claim to support such a team in the first place. Fans of rather less glamorous teams seldom account for their club affiliations in the same way. They do not "need" to do so, as they can generally assume that other parties will not in any way infer that an affiliation to, say, Leyton Orient, is borne of an ad-hoc desire to bask in the team's extensive glories. In short, within the language of English football, a speaker can reason that the claim to support a team that never wins anything is a hearable mark of authentic fandom in and of itself. The exception to this broad rule is in cases of Leyton Orient fans speaking to each other, in which case the issue of questionable authenticity may once again become operationally salient. The character of self-description, in all cases, is demonstrably contingent upon practical reasoning pertaining to the character of the local interpersonal context $[6,20]$.

"Authenticity in autobiography" is also observable in a range of moments in real sporting team-talks. Interestingly, it is most commonly used by a coach when either advancing direct criticism, or when being challenged by one or more of their charges. By explicitly occasioning autobiographical materials in this way, coaches can be seen to:

1. Reinforce their own situational authenticity as the "knowledgeable party" in the particular interaction, and thereby the authority of their knowledge itself. This may variously involve: 
2. The explicit invocation of such detail as: a) length of time spent as a coach (amount of practical experience), b) qualifications obtained (quality of theoretical knowledge) and c) previous record of success (quality of practical experience). Which of these is specially foregrounded is dependent upon:

3. The coach's own reasoning regarding how their claims might be heard, what they infer differentiates them most clearly from the particular athlete(s) they are speaking to and the knowledge that they can assume the athlete(s) hold(s) regarding their prior coaching careers. As such, for example, older coaches can potentially use all three forms of detail outlined in point 2 credibly, though will chiefly address a) as the matter of primarily importance where b) or c) could be inferably challenged by the athlete(s).

4. Because these self-descriptions do not occur in isolation, but are bound up in verbal activity sequences where a point of contention arises, they function as: i) prospective warrants for making a criticism (implicitly "I am/know/have done X, you are/do/have not, and therefore I am qualified to tell you that you are wrong here.") or; retrospective rebuttals of criticism (implicitly "How can you contest my expertise when I am/know/have done X and you are/do/have not?").

Consider, for example, extract 2 (below) ${ }^{4}$, taken from a "spirited" half-time team-talk delivered by a soccer coach to his amateur side. Something in the style of this utterance may well be familiar to many coaches and soccer players alike:

\section{Extract 2: (PD6; Soccer, Amateur, UK, 2008)}

1. Coach: I don't know what to say (.) I jus fuckin don't (.)that was

2.

3. ahh? (.) I've been doing this for fuck kno:ws

3. how long? (.) twenty odd years and (.) I've seen a lot of shit

4.

5 . but I can honestly say (.5) .hh that's the laziest fucki:ng effort ((continues))

The coach here, as described in the broad model above, orients to the potentially contentious nature of making a "big claim" about the weakness of his team's performance (lines 4 and 5) by alluding specifically to his time served as a coach (around twenty years) which is longer than some of the players, in this instance, had been alive and certainly longer than any of them had been seriously involved in soccer. In doing so, he both:

1. Attends locally to his own accountability [14] for making such a strong claim. He makes explicitly available that he is the longest-serving football person, and inferably therefore the person with the greatest authority to make such claims - in short, he insulates the criticism against possible challenge on the grounds of experience. He generates expertise within the claim. And concurrently:

2. Contextually strengthens the claim itself (the laziest effort by anyone in twenty years is hearably lazier than the team's laziest effort in, say, the last six months).

\footnotetext{
${ }^{4}$ Note that this extract is, like most data using CA and DP, transcribed using the conventions developed by Gail Jefferson [46], which are summarised at in Appendix 1.
} 
Whether he thinks the performance is the laziest he has seen in twenty years, is exaggerating or simply lying is not the issue here; rather, the language he uses is itself demonstrably contingent upon the business of making a harsh criticism of a particular group of players in a particular context, and ultimately geared towards producing a better performance in the second half.

It is of note that this use of "authenticity in autobiography" does not only arise in moments of criticism, but is also sometimes a feature of strong compliments. It is not uncommon for coaches to deploy similar types and levels of detail when describing, for example, "great performances." This indicates that this broad strategy in the language of coaching is primarily a feature of making potentially contestable claims, be they positive or negative. By directly occasioning their own claims to expertise, in terms of duration, record etc., when paying a compliment, coaches attend to the possibility that their words might be heard as an exaggeration, or a mere compliment, which would potentially undermine the motivational value thereof. Once again, the authority of the knowledge and the authenticity of the speaker are concurrently and reflexively worked-up in the talk itself.

\section{CONCLUSION}

What has been advanced here is a sort of manifesto for greater engagement with discursive psychology within the field of coaching. The point is to identify how things are done with words within complex and fluid social contexts. This does not involve quantification; after all, it would be myopic to ignore rare or ad-hoc incidences of innovative practice because they are statistically insignificant. Rather DP calls for us, as psychologists, to explore and describe the rich variety of ways in which these actions are accomplished - and coaching, it is fair to say, is primarily about action. This may be, on the surface, somewhat counterintuitive for the many of us trained to seek something "under the skull" as an explicatory resource. As Robert J. Fogelin [43] notes, this intuition in psychology bears a strong kinship with the long-standing attitude in philosophical inquiry that was so heavily criticised by Wittgenstein [33, \#314], the intuition to press on "in search of reasons when none are to be found" [42, p. 29]. Herein, and as Wittgenstein himself argues:

...the difficulty - I might say - is not that of finding a solution but rather of recognising as the solution something that looks as if it were only a preliminary to it...This is connected, I believe, with our wrongly expecting an explanation, whereas the solution of the difficulty is a description, if we give it the right place in our considerations. If we dwell upon it, and do not try to get beyond it.

The difficulty here is: to stop." [33, \#314]

The evolving perspective of DP, at its core, asks us not to further refine our existing models, but to challenge our assumptions regarding the very relationship between thought and action. Potter et al. neatly summarise this issue thusly: "It is not necessary to attribute a determinate, perhaps ultimately private, self in order to study subjectivity. What we have, readily available, is socio-linguistic discourse of all kinds...." [44, p. 159]. It is an uncomfortable ask, chiefly because a discursive psychological approach to coaching does not facilitate the kinds of prediction that a social scientist might conventionally target. As the great mathematician Benoit B. Mandelbrot argued in The Fractal Geometry of Nature [45], however, it is our expectations of precise scientific prediction that are in most cases themselves at fault, as they draw our focus away from what is and encourage an alternative focus on our own idealised (and predictable) renderings thereof. A discursive psychology of 
coaching practice holds great promise for a greater understanding of the real, everyday business of being a coach in all of its complexity and messiness. Open debate on the issue is crucial; we should probably not, like Arsène, claim to have not seen it.

\section{REFERENCES}

1. Harré, R. and Gillett, G., The Discursive Mind, Sage, London, 1994.

2. Edwards, D., Discourse and Cognition, Sage, London, 1997.

3. Silverman, D., Harvey Sacks: Social Science and Conversation Analysis, Sage, London, 1998.

4. Silverman, D., Discourses of Counselling: HIV Counselling as Social Interaction, Sage, London, 1997.

5. Sacks, H., Lectures on Conversation, Vol. 1, Blackwell, Oxford, 1992.

6. Wooffitt, R., Conversation Analysis and Discourse Analysis: A Comparative and Critical Introduction, Sage, London, 2005.

7. Sacks, H., Notes On Methodology, in: Atkinson, J.M. and Heritage, J., eds., Structures Of Social Action: Studies In Conversation Analysis, Cambridge University Press, Cambridge, 1984, 2-27.

8. Potter, J. and Wetherell, M., Discourse and Social Psychology: Beyond Attitudes and Behaviour, Sage, London, 1987.

9. Wiggins, S. and Potter, J., Discursive Psychology, in: Willig, C. and Stainton-Rogers, W., eds., The Sage Handbook of Qualitative Research in Psychology, Sage, London, 2008, 72-89.

10. Billig, M., Arguing and Thinking, $2^{\text {nd }}$ edn., Cambridge University Press, Cambridge, 1997.

11. Hutchby, I. and Wooffitt, R., Conversation Analysis: Principles, Practices and Applications., Polity Press, Cambridge, 1998.

12. Coulter, J., Language Without Mind, in: Te Molder, H. and Potter, J., eds., Talk and Cognition, Cambridge University Press, Cambridge, 2005, 79-92.

13. Faulkner, G. and Finlay, S., It's Not What You Say, It's The Way That You Say It! Conversation Analysis: A Discursive Methodology, Quest, 2002, 54(1), 49-66.

14. Garfinkel, H., Studies in Ethnomethodology, Prentice Hall, NJ, 1967.

15. Heritage, J., Garfinkel and Ethnomethodology, Polity Press, Cambridge, 1984.

16. Wooffitt, R., Telling Tales of The Unexpected: The Organisation of Factual Discourse, Harvester Wheatsheaf, Hemel Hempstead, 1992.

17. Schegloff, E.A., Reflections on Talk and Social Structure, in: Boden, D. and Zimmerman, D.H., eds., Talk and Social Structure: Studies in Ethnomethodology and Conversation Analysis, Polity Press, Oxford, 1991, 44-71.

18. Heritage, J. and Maynard, D.W., Introduction: Analyzing Interaction Between Doctors and Patients in Primary Care Encounters, in: Heritage, J. and Maynard, D.W., eds., Communication in Medical Care: Interaction Between Primary Care Physicians and Patients, Cambridge University Press, Cambridge, 2006, $1-21$.

19. Potter, J., Making Psychology Relevant, Discourse \& Society, 2005, 16, 739-747.

20. Potter, J., Cognition and Conversation, Discourse Studies, 2005, 8(1), 131-140.

21. Drew, P., Is Confusion a State Of Mind?, in: Te Molder, H.And Potter, J., eds., Conversation and Cognition, Cambridge University Press, Cambridge, 2005, 161-183.

22. Sacks, H., Lectures on Conversation, Vol. 2, Blackwell, Oxford, 1992.

23. Edwards, D. and Potter, J., Discursive Psychology, Sage, London, 1992.

24. Edwards, D. and Potter, J., The Chancellor's Memory: Rhetoric and Truth in Discursive Remembering, Applied Cognitive Psychology, 1992, 6, 187-215.

25. Edwards, D. and Potter, J., Language and Causation: A Discursive Action Model of Description and Attribution, Psychological Review, 1993, 100(1), 23-41. 
26. Locke, A. and Edwards, D., Bill and Monica: Memory, Emotion And Normativity in Clinton's Grand Jury Testimony, British Journal of Social Psychology, 2003, 42, 239.

27. Antaki, C., Finlay, W.M.L., Sheridan, E., Jingree, T. and Walton, C., Producing Decisions in Service-User Groups for People with an Intellectual Disability: Two Contrasting Facilitator Styles, Mental Retardation, 2006, 44, 322-343.

28. Antaki, C., Walton, C. and Finlay, W.M.L., How Proposing an Activity to a Person with an Intellectual Disability can Imply a Limited Identity, Discourse \& Society, 2007, 18, 393-410.

29. Locke, A., Accounting for Success and Failure: A Discursive Psychological Approach to Sport Talk, Quest, 2004, 56, 302-320.

30. Locke, A., "If I'm Not Nervous, I'm Worried, Does That Make Sense?": The Use of Emotion Concepts by Athletes in Accounts of Performance, Forum: Qualitative Social Research, 2003, 4(1), 170-185.

31. McGannon, K.R. and Mauws, M.K., Discursive Psychology: An Alternative Approach for Studying Adherence to Exercise and Physical Activity, Quest, 2000, 52(2), 148-165.

32. Lamont-Mills, A. and Christensen, S., "I Have Never Taken Performance Enhancing Drugs and I Never Will": Drug Discourse in the Shane Warne Case, Scandinavian Journal of Medicine \& Science in Sports, 2008, 18(2), 250-258.

33. Wittgenstein, L., Zettel, $2^{\text {nd }}$ edn., Blackwell, Oxford, 1981.

34. Ericsson, K.A., The Path to Expert Performance: Insights from the Masters on How to Improve Performance by Deliberate Practice, in: Thomas, P., Ed., Optimizing Performance In Golf, Australian Academic Press, Brisbane, 2001, 1-57.

35. Ericsson, K.A. and Charness, N., Expert Performance: Its Structure and Acquisition, American Psychologist, 1994, 49(8), 729-747.

36. Williams, A.M. and Ericsson, K.A., Some Considerations When Applying the Expert Performance Approach in Sport, Human Movement Science, 2005, 24, 283-307.

37. Jones, R.L., Armour, K.M. and Potrac, P., Constructing Expert Knowledge: A Case Study of a Top-Level Professional Soccer Coach, Sport, Education \& Society, 2003, 8(2), 213-229.

38. Abernethy, B., Baker, J. and Côté, J., Transfer of Pattern Recall Skills may Contribute to the Development of Sport Expertise, Applied Cognitive Psychology, 2005, 19(6), 705-718.

39. Baker, J. and Horton, S., A Review of Primary and Secondary Influences on Sport Expertise, High Ability Studies, 2004, 15(2), 211-228.

40. Garfinkel, H., A Conception of, and Experiments with, "Trust" as a Condition of Stable Concerted Actions, in: Harvey, O.J., ed., Motivation and Social Interaction, Ronald Press, New York, 1963, 187-238.

41. Widdicombe, S. and Wooffitt, R., The Language of Youth Subcultures: Social Identity in Action, Harvester Wheatsheaf, Hemel Hempstead, 1995.

42. Fogelin, R.J., Taking Wittgenstein at his Word: A Textual Study, Princeton University Press, Princeton, NJ, 2009.

43. Fogelin, R.J., Wittgenstein, $2^{\text {nd }}$ edn., Routledge \& Kegan Paul, London, 1987.

44. Potter, J., Stringer, P. and Wetherell, M., Social Texts And Context: Literature and Social Psychology, Routledge \& Kegan Paul, London, 1984.

45. Mandelbrot, B.B., The Fractal Geometry of Nature, Freeman, Oxford, 1982.

46. Atkinson, J.M. and Heritage, J., eds., Structures of Social Action: Studies in Conversation Analysis, Cambridge University Press, Cambridge, 1984. 


\section{APPENDIX 1. STANDARD JEFFERSONIAN TRANSCRIPTION SYMBOLS}

(.5) The number in brackets indicates a time gap in seconds (i.e., in this instance, five tenths).

(.) A dot enclosed in brackets indicates a pause in the talk of less than two tenths of a second.

-hh A dot before an ' $h$ ' indicates an in-breath by the speaker. More h's indicate a longer breath.

hh An ' $h$ ' indicates an out-breath. More h's indicate a longer breath.

(()) A description enclosed in double brackets indicates a non-verbal activity.

- $\quad$ A dash indicates a sharp cut off of the prior word or sound.

: Colons indicate that the speaker has drawn out the preceding sound or letter. More colons indicate a greater degree of 'stretching' of the sound.

( ) Empty brackets indicate the presence of an unclear fragment in the recording. (guess) The words within a single bracket indicate the transcriber's best guess at an unclear fragment.

A full stop indicates a stopping fall in tone, not necessarily the end of a sentence.

A comma indicates a continuing intonation.

A question mark indicates a rising inflection, not necessarily a question. An asterisk indicates a 'croaky' pronunciation of the immediately following section.

$\uparrow \downarrow \quad$ 'Up' and 'Down' arrows represent a rising or falling intonation, respectively.

CAPITALS With the exception of proper nouns, capital letters indicate a section of speech louder than that surrounding it.

o o Degree markers indicate that the talk they encompass was noticeably quieter than that surrounding it.

underline Indicates speaker emphasis 


\title{
Arsène Didn't See lt: Coaching, Research and the Promise of a Discursive Psychology
}

\author{
A Commentary \\ Jonathan Potter \\ School of Social, Political and Geographical Sciences, \\ Loughborough University, Loughborough, \\ Leicestershire, LE11 3TU, UK \\ E-mail: J.A.Potter@lboro.ac.uk
}

\section{INTRODUCTION}

Sometime in the early 1990s I taught a two-day workshop on discursive psychology (DP) in Oslo. I was intrigued and a little disconcerted that one of the top Olympic ski coaches had signed up as a participant. I wasn't sure that discursive psychology would provide helpful insight into his special set of sports and didn't want to waste his time. Indeed, at first sight an approach which starts with discourse has limited promise for studying coaching where issues of motivation, embodiment and performance are central. My Norwegian participant was very focused on the moment of 'letting go' and the precise 'angle of attack' of the skis. However, it turned out that even in the early 1990s DP could offer significant insights in this area.

My early anxiety chimed with a now familiar complaint that discourse work is 'all about talk' and thus unable to tackle topics where body issues, emotion and experience are central. Yet over the last 20 years these issues have been major topics of DP research and as I have argued recently, complaints of this kind often fail to read contemporary work and understand the way analysis is grounded in a study of the normative orders of interaction (see for example, Potter [1, 2]). Crucially, contemporary DP starts with records of interaction derived from natural settings rather than the pervasively got-up materials - interviews, surveys and experiments - that are currently the data of sports psychology. A key focus of DP is on the organization of embodied interaction, and in particular on the orientations to 'psychological' or 'bodily' matters that are displayed there. The approach draws on the insights and cumulative body of findings of conversation analysis to explicate the way 'psychological' matters appear in practical settings and are part of constituting the organization of those settings [3].

\section{SPORTS COACHING AND DISCURSIVE PSYCHOLOGY}

With respect to sports coaching, research of this kind would start with records of actual coaching sessions. These would ideally be recorded on digital video by participants themselves over a period of time sufficient for acclimatization to the recording. Such materials can be sorted, edited, slowed down, anonimized and so on as needed for different studies. Materials of this kind are extremely flexible and allow a high level of detail to be 
captured about vocal features of conduct (intonation, stress, delay and so on) as well nonvocal (eye gaze, body position, coordination with physical objects, and even some information about muscle flexing). Potter [2] provides an overview of the methodological issues in doing research of this kind. When combined with the cumulative findings of conversation analysis and DP, such materials provide a potentially generative start-point for the discursive study of sports coaching. The following are just four illustrative topic areas.

\section{MOTIVATION}

DP has a long tradition of considering accounts, justifications, excuses and the more general language of motivation and the way motivated actions are baulked. For example, recent DP work has looked at the role of 'want' constructions such as 'I don't want $\mathrm{X}$ ' in the management of particular actions [4]. This motivational language is a basic currency for interaction between coaches and sports players. This can be combined with a study with constructions of intentions and the way these may be institutionally embedded [5].

\section{INFLUENCE}

DP has increasingly focused on core areas where one party attempts to change the behaviour of another. In vernacular terms, there is a cluster of speech act categories - requests, directives, threats - where one party attempts to exercise control over another (see, e.g., [6]). Such work highlights a range of complexities where one party displays entitlement over the behaviour of another, and that entitlement is resisted or endorsed. Bound together with these issues of rights and ownership of experience is an overlay of epistemic issues. Although individuals typically have high strong epistemic rights to defining their own experiences, there are a range of technical settings where these rights are softened or subverted. For example, therapists may claim, and be treated as having, a strong technical entitlement to characterise the experience or psychological troubles of their clients. Clearly such issues are central in coaching where the behaviour of one party is the central topic of another, and both parties have different vectors of epistemic entitlement over that behaviour. Experienced coaches may display special epistemic entitlement over the experiences of their trainees; and those displays may, on occasion, be confirmed or resisted. The way these entitlements are built up or undermined is likely to be an important topic in the DP of sports coaching.

\section{EMBODIMENT}

A range of studies have looked at the way bodies and bodily sensations become part of interaction. For example, how does one party manage bodily problems of another in the context of physiotherapy [7] or how are bodily expressions such as 'eugh' normatively organized as particular kinds of assessments with regular upshots [8]. As social objects, bodies enter interaction in these ways; the challenge when an individual attempts to 'get inside the skin' of another is a practical one that is regularly managed by parents and children, doctors and patients, physiotherapists and clients. This is, of course, the challenge that is central to sports coaching, and the broader tradition of DP and interaction research provides a range of models for the rigorous examination of such interaction. Sports coaching is almost inevitably multi-modal and will require a careful integration of verbal and nonverbal materials.

\section{EMOTION}

This was traditionally seen as the contrast case to work on discourse; it was a topic necessarily beyond proper discursive research. Yet emotion has become a major recent area 
of discursive study (see, e.g., $[9,10]$ ). These studies look at the way displays of emotion are parts of particular practices, and the way recipients of such displays manage their complex epistemic rights over the 'experiences' of the other [11]. At other times they consider the practical use of particular emotion terms and constructions [12]. Again, these provide a model for considering the role of various emotion displays and avowals in coaching situations as well as studying how coaches and athletes use emotion terms and metaphors.

\section{INSTITUTIONALITY}

One of the major successes of conversation analysis over the past 30 years has been its ability to explicate the interactional organizations that constitute the nature of particular institutions - news interviews, weight management classes, child counselling (see [13] for an overview). Sports coaching itself has its set of institutional forms that would be a major focus of interactional study.

In the light of this potential, that has yet to be realized, I was delighted that Paul Miller has offered something of a manifesto for the discursive psychology of sports coaching. His article does an important service by highlighting some of the ways that DP might contribute specifically to sports coaching as well as setting the development of DP in a relevant theoretical and analytic context, particularly in relation to conversation analysis and ethnomethodology.

One area of minor difference from Miller is, I think, the extent of his emphasis on talk and language. In the target article, Miller has coaching talk as his major focus. Coaching talk is certainly important; yet, one of the powerful resources made available by sequential analysis is that it explicates the normative organization of interaction. Such an organization allows us to understand both vocal and non-vocal actions. Take the example of threats. In the case of directives or threats, the relevant preferred (structurally appropriate) action is compliance. Despite this action being the preferred next action, a threat also sets up the possibility of alternative relevant dispreferred actions. One of these is defiance. The following extract is a recording taken from a collection of threats in everyday family mealtimes.

Extract 1: Crouch 066.40

01 Mum: [An]na?

$02(1.6)$

03 Anna: U-hhuh ((more of a sob than a response))

$04(0.6)$

05 Mum: If you don' eat your dinner:, (0.4)

06 there'll be no pudding.

07 [ (1.2) ]

08 Anna: [((spits mouthful onto her plate) $)]$

09 Mum: That's horrible.

What we can see clearly from the video is Anna spitting food onto her plate. This spitting does not occur haphazardly - it happens in the slot where Mum has produced the strongest push for her to eat (line 7). It is here that Anna can be most defiant; the slot enables the act of defiance to be issued (for further discussion of such examples, see [6]). Analysis of sports coaching - with Mum and Anna replaced by coach and athlete - would start to identify the range of normative organizations, many much more subtle.

That is not to say that the analysis of language is not central. Let us consider Miller's coaching extract: 
Extract 2: PD6; Soccer, Amateur, UK, 2008

01 Coach: I don't know what to say (.) I jus fuckin don't (.) that was

02 ahh? (.) I've been doing this for fuck kno:ws Sports coaching and discursive psychology 03 how long? (.) twenty odd years and (.) I've seen a lot of shit

04 but I can honestly say (.5) .hh that's the laziest fucki:ng

05 effort ((continues))

Miller does not miss that this talk is geared to the team producing a better performance in the second half. However, how it is geared to this is worthy of further explication. Miller appropriately picks out the way the coach builds his accountability and constructs the severity of the team's performance deficit. Yet much business here is done by the terms 'lazy' and 'effort'. Lazy is a moral description (relaxing can be appropriate after a hard day's work; having a sit down before things are finished can be negatively glossed as lazy).

Moral descriptions of conduct such as this designedly project alternatives. Put another way, by using a moral description, conduct is treated as voluntary rather than forced or caused. Not only do these players need to put more effort in, but their effort up to now has been insufficient because they actively chose not to make more effort. By implication, similar conduct, with a similar failure of effort in the second half, will court moral condemnation (for a comparable discussion of moral talk being used, in this case in relationship counselling, see [12]). Note also that the term 'honestly' counters the idea that the coach is inventing this judgement for local, strategic purposes, in the way that coaches might, just as Arsène does not surprise Miller, or television viewers, when he claims not to have noticed the foul [13].

\section{CONCLUSION}

Overall, Miller is to be applauded for starting to systematically open up the field of the discursive psychology of sports coaching. What is required now is to follow the promise through with some collections of materials and build rigorous analyses of coaching conduct using those collections. The potential is there.

\section{REFERENCES}

1. Potter, J., Rereading Discourse and Social Psychology: Transforming Social Psychology, British Journal of Social Psychology, In Press.

2. Potter, J., Discourse Analysis and Discursive Psychology, in: Cooper, H., APA Handbook of Research Methods in Psychology: Vol. 2. Quantitative, Qualitative, Neuropsychological, and Biological, American Psychological Association Press, Washington, DC, 2012, 119-138.

3. Potter, J. and Edwards, D., Conversation Analysis and Psychology, in: Sidnell, J. and Stivers, T., eds., The Handbook of Conversation Analysis, Blackwell, Oxford, 2012, 701-725.

4. Childs, C., 'I'm not X, I Just Want Y': Formulating 'Wants' in Interaction, Discourse Studies, 2012, 14, 181-196.

5. Edwards, D., Intentionality and Mens Rea in Police Interrogations: The Production of Actions as Crimes, Intercultural Pragmatics, 2008, 5, 177-199.

6. Hepburn, A. and Potter, J., Threats: Power, Family Mealtimes and Social Influence, British Journal of Social Psychology, 2011, 50, 99-120.

7. Parry, R., A Video Analysis of How Physiotherapists Communicate With Patients About Errors of Performance: Insights for Practice and Policy, Physiotherapy, 2005, 91, 204-214.

8. Wiggins, S., The Social Life of 'Eugh': Disgust as Assessment in Family Mealtimes, British Journal of Social Psychology, In Press. 
9. Hepburn, A., Crying: Notes on Description, Transcription and Interaction, Research on Language and Social Interaction, 2004, 37, 251-290.

10. Peräkylä, A. and Sorjonen, M-L., eds., Emotion in Interaction, Oxford University Press, Oxford, 2012.

11. Potter, J., How to Study Experience, Discourse \& Society, 2012, 23, 576-588.

12. Edwards, D., Discourse and Cognition, Sage, London, 1997.

13. Heritage, J. and Clayman, S., Talk in Action: Interactions, Identities and Institutions, Wiley-Blackwell, Oxford, 2010.

13. Edwards, D. and Fasulo, A., "To Be Honest": Sequential Uses of Honesty Phrases in Talk-in-Interaction, Research on Language and Social Interaction, 2006, 39, 343-376. 



\title{
Arsène Didn't See lt: Coaching, Research and the Promise of a Discursive Psychology
}

\author{
A Commentary \\ Susan A. Speer \\ School of Psychological Sciences (Psychology Division) \\ Coupland Building 1, The University of Manchester \\ Oxford Road, Manchester M13 9PL, UK \\ Email: susan.speer@manchester.ac.uk
}

\section{INTRODUCTION}

Paul Miller's article provides a useful introduction to the key features of discursive psychology (henceforth DP) for a coaching audience. As Miller points out, discursive psychologists are critical of the idea that the words people speak are "straightforwardly reducible to, or representative of, cognitive operations which mediate the "real world"" (p. 618 ). Rather, the focus is on the social actions those words accomplish and their pragmatic functions in sequences of interaction in the particular social contexts that people inhabit ( $\mathrm{p}$. 618). In respect of coaching practice, these social actions may include, but are not limited to: accounting for (or predicting) success or failure, blaming or criticising poor performance, complimenting great performances and requesting or motivating enhanced performance.

Lamenting the 'lack of headway' made by DP in the field of coaching, Miller hopes his article will serve as a manifesto for greater engagement with DP in the field of coaching (p. 625). He concludes that DP "holds great promise for a greater understanding of the real, everyday business of being a coach in all of its complexity and messiness" (p. 626).

Miller demonstrates the potential value of a DP approach using data drawn from his pilot investigation of team talks. Focusing on the concept of 'expertise' he shows how coaches 'do' expertise in challenging or contentious coaching situations by invoking their coaching biography (e.g., "I've been doing this for fuck knows how long? (.) twenty odd years", Extract 2). For Miller, such claims may be used to bolster arguments designed to motivate the team to produce "a better performance in the second half" (p. 625), protecting them against rebuttals on the grounds of (limited) experience that would undermine their 'motivational value'. Miller notes that invoking one's expertise in this way is not limited to moments of criticism, but can also occur in situations where coaches compliment great performances. Therefore, the use of "authenticity in autobiography" is a feature of "potentially contestable claims, be they positive or negative" (p. 625).

Miller's article makes a persuasive theoretical argument for, and methodological demonstration of, the contrast between a social-cognitive and a discursive approach to expertise within coaching, highlighting "how the character of authoritative knowledge asproduced is always indivisibly bound to the social context of its production" (p. 623). However, I want to argue that it stops short of answering what I take to be the potential 'so 
what?' questions of his target audience. That is: what is the relevance and value of a DP analysis of expertise for Miller's "real, everyday business of being a coach in all of its complexity and messiness" (p. 626). How, precisely, can a DP approach be used to help solve the real world problems and issues affecting coaches in applied coaching contexts? And how can coaches use insights from DP for the benefit of their teams, and in order to enhance performance? For me, the potential impact of Miller's manifesto is limited because of his almost exclusive focus on, and interpretation of his data in terms of, the notion of 'expertise'. In the remainder of this commentary, I point to several lines of inquiry that could open up 'the promise of DP' for researchers and coaches with an interest in improving coaching communication in applied contexts.

\section{USING DISCURSIVE PSYCHOLOGY TO IMPROVE COACHING COMMUNICATION IN APPLIED CONTEXTS}

First, more could be said about the multi-unit turn in Miller's target extract: In addition to establishing the coach's expertise via a reference to the time he has served as a coach, the coach's criticism of the team's performance contains a range of compositional features of interest to DP and Conversation Analysis (henceforth CA): At the start the coach invokes, not expertise, but a lack of knowledge ('I don't know what to say' [1]). He makes a negative assessment of the players' performance ('laziest fucking effort' [2]), formulated using 'honesty' phrases [3] in a designedly extreme way [4]. These features appear to be deployed together, alongside the autobiographical and experiential claims, in the service of enhancing the (potentially contestable) credibility of the coach's evaluation of the team's performance. Second, although such analyses are interesting in and of themselves, in order to make claims about interactional data that will impact the field of coaching, analyses need to extend further than the "range of highly nuanced and skilled interpersonal methods used by coaches in constituting their knowledge and, reflexively, themselves as authentically and authoritatively "expert"" (p. 623). Although the reader does not have access to the full interactional sequence of which Extract 2 forms a part, as much CA work demonstrates, in order to gain a more complete understanding of the social actions that a speaker's turn embodies, and produce findings that can be applied to problems and issues in real world contexts, one needs to go beyond a focus on compositional features of the first turn at talk, to consider sequential aspects of the coaching interaction, including recipients' uptake, or response to (and the interactional outcome of), that turn at talk (for examples of applied CA, see [5]).

For me, unanswered questions about Extract 2 include: Do the team members treat what the coach says as a criticism - in which case one might expect them to respond with accounts that serve to justify or defend their poor performance? Or do they treat it as a motivational speech, for example, by agreeing with the coach's negative assessment of their performance and promising to 'up their game' in the second half? Or some combination of both? What, in essence, is the interactional outcome of this kind of team talk at half time? And does this interactional outcome translate into the expression of greater player motivation and enhanced performance on the pitch?

Elsewhere in his article, Miller does appear to talk about outcomes: He speculates that requesting a player "pull their socks up" or admonishing "we can still win this" or "you can do better than that" can motivate players and "engender some mode of positive outcome" ( $\mathrm{p}$. 621; emphasis added). However, since this claim is based on decontextualised, one line data examples stripped of their interactional context, it is impossible to examine such outcomes.

Finally, perhaps the key to DP making headway in a very practically oriented field like coaching, with "the task focused character of many naturally-occurring verbal activities in 
the domain" (p. 621) is to ask a different, more ambitious set of research questions that speak very directly to the day-to-day lives of coaches and the problems and issues that they encounter on the ground. There are parallels here between the potential applications of DP in the field of coaching communication where the goal is to motivate people to produce better performances, and my own work applying CA within the field of health psychology to improve clinical communications that aim to motivate patients to engage in positive health behaviours: Key questions might include: i) 'what counts' as a successful coaching interaction? Which interactional practices, or communication techniques work well and which work less well in terms of motivating players and enhancing performance?; ii) what are coaches and sports people's views and perceptions of i)?; do their perceptions of what works well and what works less well in their half-time team talks and performance review meetings reflect the patterns of communication in the actual coaching interactions?; iii) what do coaches and sports people perceive as the barriers and challenges to communicating effectively about performance issues?; and iv) how might we use our data and findings to make practical recommendations that will enhance coaching practice and performance outcomes, and inform communication skills training for coaches across a range of fields?

\section{CONCLUSION}

DP may not have made the kind of headway in the field of coaching that Miller and others hope for, because researchers have not been asking the kinds of questions that would market DP's potential within this very practical, task-oriented field. In order to avert missed opportunities and fulfil DP's 'great promise', discursive researchers might consider asking the kinds of questions that will move us closer to producing findings that may be of benefit to, and make a difference in, coaching practice.

\section{REFERENCES}

1. Weatherall, A., I Don't Know as a Prepositioned Epistemic Hedge, Research on Language \& Social Interaction, 2011, 44(4), 317-37.

2. Pomerantz, A., Agreeing and Disagreeing with Assessments: Some Features of Preferred/Dispreferred Turn Shapes, in: Atkinson, J. M., and Heritage, J., eds., Structures of Social Action: Studies in Conversation Analysis, Cambridge University Press, Cambridge, 1984, 57-101.

3. Edwards, D. and Fasulo, A., “To Be Honest”: Sequential Uses of Honesty Phrases in Talk-in-Interaction, Research on Language and Social Interaction, 2006, 39 (4): 343-76.

4. Edwards, D., Extreme Case Formulations: Softeners, Investment, and Doing Nonliteral, Research on Language and Social Interaction, 2000, 33 (4), 347-73.

5. Antaki, C., ed., Applied Conversation Analysis: Intervention and Change in Institutional Talk, Palgrave Macmillan, Basingstoke, UK, 2011. 



\title{
Arsène Didn't See lt: Coaching, Research and the Promise of a Discursive Psychology
}

\author{
A Commentary \\ Guy Faulkner ${ }^{1}$ and Sara-Jane Finlay ${ }^{2}$ \\ ${ }^{1}$ Faculty of Kinesiology and Physical Education, University of Toronto, \\ 55 Harbord Street, Toronto, Ontario, Canada, M5S 2W6. \\ E-mail: guy.faulkner@utoronto.ca \\ ${ }^{2}$ Office of the Vice President and Provost, Faculty and Academic Life, \\ University of Toronto, 12 Queen's Park Crescent, Toronto, \\ Ontario, Canada, M5S $1 \mathrm{~A} 1$. \\ E-mail: sarajane.finlay@utoronto.ca
}

\section{INTRODUCTION}

Let's be upfront - we are Manchester United fans. For Faulkner, an Australian living in Toronto, Canada, who has never been to Old Trafford, this statement is followed by the explanation that his father was born in Manchester. For Finlay, a Canadian with no connection to Manchester, this statement includes reference to the fact that all three of her children are named after Man U players (specifically those directly involved in the goals scored against Bayern Munich in the 1999 Champions League Final). As Paul Miller illustrates in his article on the promise of discursive psychology for coaching science these statements can be seen as bolstering the case that we are 'true' rather than fair-weather fans. For discursive psychologists, the team we support is secondary to the way we construct that support, for example, in our case we make claims of ancestry and dedication. Discursive psychology (DP) is solely focused on what is oriented to and made relevant by the participants in social interaction. For some, it is at this interactional level where the 'action' is located [1].

\section{CONVERSATION ANALYSIS}

We appreciate Miller's summary of the basic tenets of a discursive psychology approach and agree that it has much to contribute to the broader study of coaching science. Given that much of a coach's work is achieved through interacting with his or her players - for example, persuading, instructing, praising, punishing - these interactions provide a rich opportunity for exploring what is being accomplished through conversation. We published a similar commentary [2] advocating for a greater consideration of a discursive methodology for sport, exercise and physical education. Our interest was in conversation analysis, the most microanalytic variety of discourse analysis. Using this form of analysis, we sought to understand attributions in conversation (i.e., how athletes account for a win or a loss) [3, 4]. As researchers, when we look at attributions produced in conversation, we are concerned with what is actually being accomplished by and through talk. Specifically, attributions (and 
indeed common social psychological constructs such as attitudes, emotions, cognitions) are discursive actions. Asking an athlete "why" they won or lost may create interactional difficulty that must be managed in conversation. Questions about losing are a potentially 'face-threatening act', and we present data that demonstrates how the questioner and the respondent employ devices such as repetition, hedging, and offer subtle indicators of agreement when managing such a conversation [5].

\section{DISCURSIVE ACTS VERSUS COGNITIVE ENTITIES}

Notably, our original commentary article[2] has been cited an underwhelming seven times in the last ten years based on Scopus Citation Tracker. A recent systematic review of themes in sport attribution research completely failed to acknowledge discursive approaches either in the past or in the future landscape of attribution research [5]. Our modest efforts have not exactly lead to an explosion of interest in discursive approaches within sport and exercise psychology, and we are somewhat pessimistic concerning Miller's efforts in the realm of coaching science.

Why? First, quite a considerable shift needs to be taken by the researcher in that DP could be considered anti-cognitive [6]. As Miller indicates in the target article, answers are not to be found 'under the skull' (p. 622) or 'in your head'. For those well-versed with social psychological theories related to intentions, goals, attitudes, and attributions common to many coaching and sport psychology textbooks, it now becomes necessary to consider these as discursive acts rather than cognitive entities. The focus is not on whether words describe some inner state or cognitive process but rather what people are doing with their words, and the intricate orderliness of everyday talk. For some, this is an insurmountable hurdle. In the context of sport attributions, Rees et al. write that, "attributions can and should be studied as cognitive entities" [7, p. 214] and, for them, that is the end of the discussion. This might be related to two limitations which Rees et al. infer are associated with a discursive approach the inability to arrive at generalizable conclusions, and its seeming inability to provide the basis for effective interventions. These are frequent criticisms of discursive psychology and something that a number of discursive psychologists have recently challenged.

\section{IMPACT OF DISCURSIVE PSYCHOLOGY ON SOCIAL PSYCHOLOGY}

An upcoming special issue of the British Journal of Social Psychology celebrates the 25-year anniversary of the Discourse and Rhetoric Group (DARG) in the Department of Social Sciences at Loughborough University (as another example of 'authenticity in autobiography' and the buttressing of credibility, we can disclose that one of us [Finlay] was a member of this group in the late 1990s). A series of articles considers the impact of discursive psychology on social psychology. Leading authors in the field provide eloquent rebuttals of some of the common misperceptions regarding discursive psychology. For example, generalization in DP might be considered the identification of normative practices in discourse [8]; the focus of DP is understanding how everyday social interaction is normoriented rather than causally produced [9]; and findings can be and often are applied. As Stokoe et al. write, discursive psychology and conversation analysis "are powerful tools for implementing social change, particularly when the matter at hand comprises recurring interactional business", and as such they "might reveal where interactional practices go 'wrong', and how they might be put 'right'" [10, p. 2]. The authors provide a range of examples of how the detailed study of interactional practices in institutional settings (dispute mediation, child protection, and disabilities support service) can inform interventions to 
improve interactions between practitioners and clients. From a practical perspective for coaching science, the critical issue is whether coaches can become more aware of (and thus potentially more responsive to) common rhetorical strategies and the nuances of conversational interaction in their coaching practice [3].

\section{DISCURSIVE PSYCHOLOGY AND SPORTS COACHING}

This special issue [12] is strongly recommended for readers to learn more about DP and its shift to the mainstream of social psychology. That shift is not clearly evident within the field of sport and exercise psychology, although presumably for DP theorists this is inconsequential. The types of normative practices described in their work are no more or no less likely to occur during interactions between coaches and athletes, or physical education teachers and students, or for that matter, a conversation during a family dinner. Indeed, our analysis of attributions in sporting contexts highlighted several issues common to conversation analytic analyses of attributions in general, for example, the interactional modesty inherent in discussing wins and the 'slipperiness' of attributions in conversation [3]. That is, we did not find anything novel about asking athletes why they won or lost that Charles Antaki [1] might not have reasonably predicted in the first place. In his article, Miller essentially 'spots' structural features of talk including the use of rhetorical strategies deployed when a contestable claim is made.

There are also a number of practical barriers. First, to do DP or conversation analysis well requires a great deal of painstaking time and effort. We warn readers that it is not easy! Nor should it be - it is a rigorous and sophisticated form of analysis. However, in the broader climate of research audits and evaluations where output is the currency, 'doing' discursive psychology (in our case, conversation analysis) is very rewarding, but more time consuming than both traditional quantitative and (many) qualitative approaches. It is also probably not something that one can teach oneself (see [11] for a discussion of this); at the least, it would be advisable to have mentor(s) and colleagues interested in sharing and supporting data analysis, a forum that the DARG group continues to provide. Second, our feeling is that a discursive approach is not for the dilettante - it requires commitment to discursive psychology as a 'distinct way of doing psychology' [12]. As Billig describes [13], discursive psychology is not just something to do but also something to $b e$; discursive psychologists are an identifiable type of academic. From a DP perspective, all potential research questions are always and necessarily framed by discursive interaction. Such a perspective might not be attractive for the more methodologically promiscuous among us who like to dabble in a range of research questions and methodologies.

\section{CONCLUSION}

We do not mean to be too disheartening about DP. None of the issues we describe are insurmountable. DP has made a significant impact on social psychology particularly in terms of highlighting the value of a focus on everyday conversations and social interactions. We agree with Miller that more frequent engagement with DP in coaching science might provide the basis for a greater understanding of the 'business' of coaching. We will follow developments with interest.

\section{REFERENCES}

1. Antaki, C., Explaining and Arguing: The Social Organisation of Accounts, Sage, London, 1994.

2. Faulkner, G. and Finlay, S-J., It's Not What You Say, it's the Way that You Say it! Conversation Analysis: A Discursive Methodology, Quest, 2002, 54, 49-66. 
3. Finlay, S-J. and Faulkner, G., "It Wasn't Me!": Managing Attributions in Conversation, Forum: Qualitative Social Research, 2003, 4(1), 15-24.

4. Faulkner, G. and Finlay, S-J., Attributions and Accountability: A Rejoinder to Rees, Ingledew \& Hardy (2005), Psychology of Sport and Exercise, 2005, 6, 205-211.

5. Allen, M.S., A Systematic Review of Content Themes in Sport Attribution Research: 1954-2011, International Journal of Sport and Exercise Psychology, 2012, 10(1), 1-8.

6. $\quad$ Edwards, D., Discourse and Cognition, Sage, London, 1997.

7. Rees, T., Ingledew, D.K. and Hardy, L., Attribution in Sport Psychology: Further Comments on Faulkner and Finlay (2005), Psychology of Sport and Exercise, 2005, 6, 213-214.

8. Potter, J., Re-reading Discourse and Social Psychology: Transforming Social Psychology, British Journal of Social Psychology, 2012, 51(3), 436-455. 10.1111/j.2044-8309.2011.02085.x

9. Edwards, D., Discursive and Scientific Psychology, British Journal of Social Psychology, 2012, 51(3), 425435. 10.1111/j.2044-8309.2012.02103.x

10. Stokoe, E., Hepburn, A. and Antaki, C., Beware the "Loughborough School"? Interaction and the Politics of Intervention, British Journal of Social Psychology, 2012, 51(3), 486-496. 10.1111/j.2044-8309.2011.02088.x

11. Antaki, C., Billig, M. G., Edwards, D. and Potter, J. A., Discourse Analysis Means Doing Analysis: A Critique of Six Analytic Shortcomings, Discourse Analysis Online, 2003, 1(1), Retrieved $13^{\text {th }}$ June 2012 from http://extra.shu.ac.uk/daol/articles/v1/n1/al/antaki 2002002-t.html

12. Augoustinos, M. and Tileaga, C., Twenty Five Years of Discursive Psychology, British Journal of Social Psychology, 2012, 53(3), 405-412. 10.1111/j.2044-8309.2012.02096.x

13. Billig, M.,Undisciplined Beginnings, Academic Success, and Discursive Psychology, British Journal of Social Psychology, 2012, 51(3), 413-424. 10.1111/j.2044-8309.2011.02086.x 


\title{
Arsène Didn't See lt: Coaching, Research and the Promise of a Discursive Psychology
}

\author{
A Commentary \\ Abigail Locke \\ School of Human \& Health Sciences, University of Huddersfield, \\ Queensgate, Huddersfield, HD1 3DH, UK \\ E-mail: a.locke@hud.ac.uk
}

\section{INTRODUCTION}

In the target article, Paul Miller sets out to describe the approach within social psychology known as discursive psychology. He takes the reader from an opening anecdote from Arsène Wenger and 'clouded perceptions'/'disavowals of memory', to a wider discussion of the principles underlying discursive psychology, and an overview of a particular type of discursive psychology - from Harvey Sacks, the Discursive Action Model [1] and conversation analysis (CA).

\section{DISCURSIVE PSYCHOLOGY AND SPORTS COACHING}

Miller is correct in his assertion that discursive psychology (DP) has much to offer the study of sports coaching and his paper outlines the key assumptions behind a discursive approach. $\mathrm{He}$ notes that discursive psychology has been "actively applied to the broader study of sporting phenomena with instructive results" (p. 621), drawing on some previous work by myself and others that has focused on topics that originated within social psychology such as emotion [2], memory [3] and attribution [4,5], applying key principles and concepts from social psychology to sports psychology. However, he touches on this work all too briefly, yet all of these published works can be viewed as offering examples of some of the claims specifically made about DP and sport. Indeed there are examples of more recent work that also demonstrate DP as applied to sport that seem to have been overlooked here. Therefore I would suggest that a two-fold approach is needed in order to develop this area further.

Firstly, a stronger demonstration of data from specific coaching settings to illustrate and back up Miller's claims would be beneficial as it would locate some of the key concepts that are outlined within the paper, and, as such, would further Miller's introduction into the area. Secondly, a more thorough engagement with the research literature in this area would greatly benefit the claims made and strengthen the arguments around applying discursive psychology to sport. Miller notes that there is scant literature in the area. In some aspects, this is correct. However, the research work that has been conducted within sport psychology has been greatly informative to specific areas within sport and a more in-depth investigation of this literature and what it has to offer would be most useful. I will pick up this at a later point.

I felt that the article demonstrated a certain lack of clarity for both the specificities of the method and the topic of investigation: i.e., sporting performance, comments on sporting 
performance or coaching interactions. The Arsène quote is a matter of accounting in a public sports interview, something that previous research has commented on [6]. For example, memory disavowals, whereby people claim not to remember, or, as in this case, clouded perceptions, where people claim events have not been seen, have been well documented as a means of accounting in discursive studies around memory, attributions and accountability $[1,4,7,8]$. They serve, as Edwards and Potter note [1], in their classic text to demonstrate 'plausible deniability'. That is, the actor, in this case Arsène, cannot be as easily held to account for something that he has not seen, or indeed, cannot remember.

While Miller instructs us that the focus is on what discursive psychology can offer the study of coaching as a methodology, he only produces two extracts of data, and one of these is not directly relevant to coaching, instead it is from Harvey Sacks on telephone calls to an emergency helpline (to demonstrate a principle of CA). The other piece of data is drawn from a coaching interaction. It would be most useful to have more examples from specific cases of coaching interactions in order to see the discursive method tried and tested in this particular setting.

\section{SECOND-WAVE DISCURSIVE PSYCHOLOGY}

In essence, the type of discursive psychology that Miller is proposing for a study of coaching is second-wave discursive psychology [1], and while this particular method has not been applied directly to coaching interactions, it has been applied to sports performers accounts of performance more generally [9] with transferable claims. The 'second-wave' discursive psychology that is proposed in this article has now moved on in its focus. Some, including Edwards and Potter themselves, have moved away from the Discursive Action Model (DAM) model [1] and moved towards a more explicitly conversation analytic perspective, while others, myself included, have moved towards a hybrid of discursive approaches - utilising discourse analysis in all of its forms and considering Foucauldian readings of discourses. The hybrid discursive approach has been conducted in sport and exercise psychology by Kerry McGannon and colleagues [10,11], but any of their claims could be transferred to the coaching setting. Conversation analysis (CA) as a method has much to offer the study of coaching interaction as it focuses on naturally occurring interactions. Indeed there are some studies already within the sporting realm that can offer transferable insight into this area. For example, Jimmerson [12] offered a CA re-analysis of team-locker room data (and see also [13]. The instructive work of Amanda LeCouteur within discursive sport psychology recently has begun to explore specifically what CA can offer to the actual real-time study of competitive sports performance with interesting results [14], thus demonstrating a strong applicability of the discursive and CA methodologies to the study of sports practice - both coaching and actual performance. In addition, recent work by Zucchermaglio and Alby [15] used a discursive perspective to study identity in sports teams and, from doing an ethnographic study of a soccer team for a few months, recorded various interactions, including coaching sessions. Finally, Cosh et al. [16] have recently applied the actual study of CAinspired DP to athlete training interactions, in particular skin-fold testing for athletes.

\section{CONCLUSION}

A discursive approach to the sporting realm, including in-depth studies on coaching and performance interactions has much to offer. In the case of Miller's article here and plans for future work, I feel that a much fuller engagement with some of the existing discursive work in sport might be beneficial for considering more nuanced and specific future research directions in this area. 


\section{REFERENCES}

1. Edwards, D. and Potter, J., Discursive Psychology, Sage, London, 1992

2. Locke, A., 'If I'm not Nervous, I'm Worried, Does that Make Sense?': The Use of Emotion Concepts by Athletes in Accounts of Performance, Forum: Qualitative Social Research, 2003, 4.

3. Locke, A., Managing Agency for Athletic Performance: A Discursive Approach to the Zone, Qualitative Research in Psychology, 2008, 5, 103-126.

4. Finlay, S.J. and Faulkner, G., "Actually I was the Star": Managing Attributions in Conversation, Forum: Qualitative Social Research, 2003, 4.

5. Faulkner, G. and Finlay, S.J., Attributions and Accountability: Comments on Rees, Ingledew and Hardy, Psychology of Sport and Exercise, 2005, 6, 205-211.

6. Emmison, M., Victors and Vanquished: The Social Organization of Ceremonial Congratulations and Commiserations. Language and Communication, 1987, 7, 93-110.

7. Locke, A. and Edwards, D., Bill and Monica: Memory, Emotion and Normativity in Clinton's Grand Jury Testimony, British Journal of Social Psychology, 2003, 42, 239-256.

8. $\quad$ Edwards, D., Discourse and Cognition, Sage, London, 1997.

9. Locke, A., Accounting for Success and Failure: A Discursive Psychological Approach to Sport Talk, Quest, 2004, 56, 302-320

10. McGannon, K. and Mauws, M., Discursive Psychology: An Alternative Approach for Studying Adherence to Exercise and Physical Activity, Quest, 2000, 52, 148-152.

11. McGannon, K. and Spence, J.C., Speaking of the Self and Understanding Physical Activity Participation: What Discursive Psychology Can Tell Us about an Old Problem, Qualitative Research in Sport and Exercise, 2010, 2, 17-38.

12. Jimmerson, J.B., A Conversation (Re)analysis of Fraternal Bonding in the Locker Room, Sociology of Sport Journal, 2001, 18, 317-338.

13. Faulkner, G. and Finlay, S.J., It's Not What You Say, it's the Way that You Say It! Conversation Analysis: A Discursive Methodology, Quest, 2002, 54, 49-66.

14. LeCouteur, A. and Feo, R., Real-Time Communication During Play: Analysis of Team-Mates' Talk and Interaction, Psychology of Sport and Exercise, 2011, 12, 124-134.

15. Zucchermaglio, C. and Alby, F., Identity in Sport Teams, Psychology, 2011, 2, 202-209.

16. Cosh, S., Crabb, S., LeCouteur, A. and Kettler, L., Accountability, Monitoring and Surveillance: Body Regulation in Elite Sport, Journal of Health Psychology, 2012, 17, 610-622. 
